\title{
A simple and intuitive methodology for estimating red blood cell surface antigen expression variation using optical cell-detachment technique
}

CHIH-LANG LIN ( $\nabla$ cllin101943@ctust.edu.tw )

Central Taiwan University of Science and Technology

SHYANG-GUANG WANG

Central Taiwan University of Science and Technology

MENG-TSUNG TIEN

HomeRun BioTech Inc.

CHUNG-HAN CHIANG

Central Taiwan University of Science and Technology

YI-CHIEH LEE

Central Taiwan University of Science and Technology

PATRICE L. BALDECK

ENS Lyon, Laboratory of Chemistry

CHOW-SHING SHIN

National Taiwan University

\section{Research Article}

Keywords: red blood cell, surface antigen expression, cell-detachment, optical tweezers

Posted Date: October 29th, 2021

DOI: https://doi.org/10.21203/rs.3.rs-134189/v2

License: (9) This work is licensed under a Creative Commons Attribution 4.0 International License.

Read Full License 


\section{Abstract}

The analysis of surface antigens on cells, especially red blood cells (RBCs), has attracted increasing attention due to the recognition of antigenic variation that can facilitate early diagnoses. This paper presents an alternative methodology to estimate the variation of surface antigen expressions using an optical cell-detachment technique to validate the binding of individual RBCs stuck on corresponding antibody-coated surfaces. The detachment tests were implemented by an optical tweezers with gradually decreasing laser powers associated with serial antibody dilutions. Then, the antigen expression variation was estimated based on the known antibody dilution folds. The B- and B3-types of RBCs were selected for the demonstration subjects. With the semi-quantitative analysis, the proposed methodology was successfully verified for evaluating the variation of the RBC surface antigen expressions. The analysis result shows good consistency with the literature's findings.

\section{Introduction}

Numerous antigens composed of peptides, proteins, and other molecules are present on the cell surface. The antigens are the critical molecular markers of cell functions and lineages[1]. The antigenic change in quantity is crucial, especially for hematologic development, immune response, and tumor progression [24]. For instance, the human leukocyte antigens (or $C D$ antigens) expressed on immune cells participate in or perform functions in the immune response [5]. RBCs can be classified by ABO blood group system based on inherited differences and expression in cell surface antigens [6]. Also, many reports have shown that blood group antigen expression is correlated with tumor progression [7-9].

Flow cytometry and enzyme-linked immunosorbent assays (ELISA) have been developed for the analysis of cell surface antigens. For instance, the flow cytometric analysis results performed by Cho et al. reveals that the transfect expressed $35.5 \%$ of the total B antigen produced on the B101 allele transfect [10]. Chen et al. showed that the percentage of B antigen expression on B3 cells is $40.92 \%$ of B1 [11]. However, the conventional methods have limitations due to low sensitivity and the need for large clinical samples $[12,13]$. For example, flow cytometry requires more than 5,000 to 10,000 copies of the target antigen on one cell to ensure quantitative analysis ${ }^{[12]}$, whereas 50,000 cells per well are needed for ELISA to obtain high optical density values and low background noise during detection [14].

More recently, the focus is shifted to the individual cell analysis to minimize sample size and enhance sensitivity. Subsequently, the optical tweezers and atomic force microscope (AFM) have been widely employed to the single-molecule biophysics research [15-18]. Optical tweezers, in contrast to AFM, are useful for single cell manipulation with precise force measurement [15]. The exerted force of optical tweezers is in the range of pico-Newton to nano-Newton scales and is resulted from the laser interaction with dielectric micro-object, with optical force ranges in the pico-Newton to nano-Newton scales. In 1989, direct trapping of RBCs using optical tweezers was reported in the pioneering works of Ashkin et al. [19]. Subsequently, optical tweezers are now being used in the investigation of an increasing number of biochemical and biophysical processes [20-30]. Many easy-to-use commercial products of optical 
tweezers have been promoted. Although optical tweezers has been widely used as a manipulation tool in interdisciplinary fields, it is still rare to employ this technology as a biosensor by the "detachment" operation.

In this study, we extended our preliminary sequent works [31-33] based on the specific antigen-antibody interactions principle and optical manipulation technique to develop an alternative methodology for estimating the variation of antigen expressions on RBCs. Herein, the optical tweezers was employed as a biosensor to detach an individual RBC off from an antibody-coated surface with serial dilution folds and laser powers for detecting the RBC binding.

\section{Materials And Methods}

\subsection{Preparation of RBCs and antibody-coated slides}

Standardized RBCs were provided by Formosa Biomedical Technology Corp. (Taipei, Taiwan) and diluted 800 fold with PBS before the addition of $0.1 \mathrm{~g} / \mathrm{ml}$ BSA to prevent the RBCs sticking together and block non-specific interactions with antibodies or the slide. One drop $(\sim 0.02 \mathrm{ml})$ of the RBCs solution was incubated on the antibody-coated slides for 20 minutes at room temperature just prior the measurement.

The antibody-coated slides were prepared by protein adhesion on surfaces coated with poly-L-lysine [34,35], an efficient method to prepare antibody microarrays [36]. Cover slides (Paul Marienfeld GmbH \& Co. $\mathrm{KG} /$ Germany) were cleaned with acidic alcohol ( $1 \% \mathrm{HCl}$ in $70 \%$ ethanol), rinsed thoroughly in ultrapure $\mathrm{H} 2 \mathrm{O}$, incubated at room temperature in a 1:10 poly-L-lysine solution (Sigma-Aldrich \#P8920) for 5 minutes, and then dried in a $60^{\circ} \mathrm{C}$ oven for 1 hour. Solutions of anti-A and anti-B monoclonal antibodies (1 $\mathrm{mg} / \mathrm{ml}$ ) were provided by Thermo Fisher Scientific Inc. (Waltham, USA) and diluted with PBS solutions (Sigma-Aldrich \#P4417) with serial dilution folds. Poly-L-lysine coated slides were incubated in antibody solutions at room temperature for 1 hour, then for 5 minutes in $0.05 \mathrm{~g} / \mathrm{ml}$ BSA solution to block nonspecificity and stored at $4^{\circ} \mathrm{C}$.

\subsection{Optical tweezers for RBC manipulation}

The schematic of the optical tweezers system based on an inverted microscope platform (Olympus IX51) is shown in Figure 1. A continuous-wave Nd-YAG laser (Onset Electro-Optics, model \# ISF064-1000P) at $\lambda=1064 \mathrm{~nm}$ focalized by a high NA (1.3) microscope objective/oil (UPLFLN100XO2, Olympus) provides the trapping beam with minimum and maximum available powers of $4 \mathrm{~mW}$ and $250 \mathrm{~mW}$, respectively. Herein, the laser power was measured at the microscope objective. The RBCs solutions were confined to an isolated sample chamber comprising two cover slides (170 $\mu \mathrm{m}$ thickness), and a double-faced tape (120 $\mu \mathrm{m}$ thickness) to eliminate flow disturbance. The chamber can be moved with an XYZ-axis nanopositioner (Physics Instrument, NanoCube®P611), while the laser is focused at a fixed position in 
the chamber. The optical dragging speed was kept low $(5 \mu \mathrm{m} / \mathrm{sec})$ for the static test during detachment, so the solution viscous effect can be ignored.

The basic principle of optical tweezers to produce optical forces for manipulating micron-sized dielectric objects have been described previously [37-39]. A laser beam is focused by a high numerical aperture (NA) of a microscope objective to a spot (less than $1 \mu \mathrm{m}$ ) in a transparent micro-object, generating an optical trapping force. The force $(F)$ can be expressed as, where $P$ is the laser power, $n$ is the relative refractive index, is a dimensionless parameter related with object dimension, NA, wavelength, polarization, beam profile, and spot size. Essentially, $1 \mathrm{~mW}$ of laser power approximately generates $1 \mathrm{pN}$ force for a $1 \mu \mathrm{m}$ diameter sphere [40]. In this study, the experiment subject, RBC, is $7.5 \sim 8.5 \mu \mathrm{m}$ in diameter, with a width of 1.7 2.2 $\mu \mathrm{m}$ in the ring and 0.5 1 $\mu \mathrm{m}$ at the center [41]. During cell-detachment testing, the optical trapping spot exerts at a constant volume at the ring edge of an attached RBC. And, the relative index $(n)$, the NA, the wavelength, the polarization, the beam profile, and the spot size are consistent in the experiment with the same optical tweezers laser and medium. Hence, the parameter is constant so that the optical force $(F)$ is linearly proportional to the laser power $(P)$.

\subsection{Demonstration of RBC detachment}

First, the negative control experiment, i.e. the case of non-specific antibody-antigen interaction was performed. Figure 2.(a) schematically illustrates a non-attached RBC trapped by optical tweezers, showing the RBC is vertically aligned by the optical torque (Figure 2.(b)). The suspended RBC can be freely dragged by the optical tweezers in solution (Figure 2.(c)) at the threshold power, i.e. $4 \mathrm{~mW}$. The sequent films of the manipulation are shown in Fig. 2d. In contrary, when the RBC antigens specifically interact with the antibody-coated surface, the RBC attaches to the slide (Figure 3.(a)). For example, Figure 3.(b) represents an A-type RBC stuck on the anti-A-coated surface even using the maximum available power $(250 \mathrm{~mW})$ of optical detachment. The basic qualitative tests of specific antibody-antigen interactions were verified using blood types $A, B$, and $O$ (Table 1.). The RBC samples were dropped on the functionalized slides coated with the associated anti-A and anti-B antibodies. The criterion of celldetachment demonstration is strict. Each test repeated at least 5 times for 5 cells, that is, 25 continuous trials to validate the antigen-antibody binding (marked as $₫$ ). In other words, once a RBC was detached in

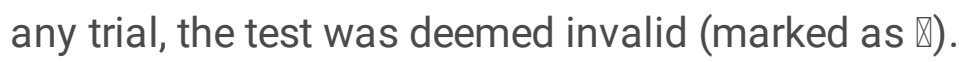

Table 1. Basic qualitative tests of specific antibody-antigen interactions using optical detachment (250 $\mathrm{mW})$

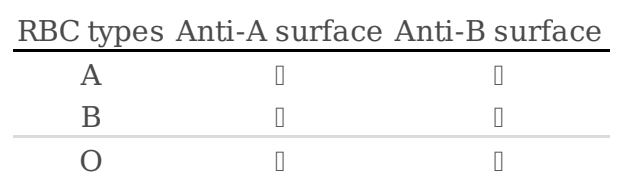

$\square$ : RBC binding validated; $\square:$ RBC detached 


\subsection{Antibody dilution method}

The "antibody dilution method" was specially proposed in this study. The binding strength between an RBC and an antibody-coated surface, i.e. RBC-antibody affinity, is proportional to the antibody-antigen associations, which depends on the quantities of the antigens/RBC surface and the antibodies/functionalized surface. Once the binding condition is validated by the cell-detachment test, the antigen expression variation can be estimated with the known antibody dilution folds.

Serial slides coated with decreasing antibody concentrations were prepared by dilution and stored at $4^{\circ} \mathrm{C}$ before testing. The dilution folds increase by an exponent of 2 , but will be adjusted according to the test requests. For example, the dilution folds increase by 512 after 2048, such as $2560,3072,3584$...etc for getting more precise testing. The RBC-antibody affinity was quantified by the highest dilution at which the RBCs could not be detached by the optical tweezers from the functionalized surface.

\section{Results And Discussions}

\subsection{Optically detachment tests with dilution method}

Rare blood group (e.g. subtype) discrepancies occur when antigens -A and -B have a weak expression, i.e. there are much fewer antigens at the RBC surface [42]. In this study, A- and B-type RBCs were selected as the subjects to implement the optical cell-detachment method. B3-type RBCs, the most common B subtype in the Asian population [11] were selected as the subject to compare the antigen expression variation with B-type RBCs.

The detection strategy includes two steps. First, the antibody concentration is high enough to interact with all the antigens at the contacted part of an RBC surface. The quantity of the antibody-antigen bindings is consistent. The stuck strength of an RBC on the functionalized surface is large enough to oppose the optical detaching pull even using the highest power $(250 \mathrm{~mW})$. In the sequent tests, as the antibody concentration becomes lower by dilution, the quantity of the antibody-antigen bindings is gradually decreasing until the RBC can be detached using the power of $250 \mathrm{~mW}$. At this time, the antibody dilution fold reaches a critical value. The results listed in Table 2. indicate that A- and B-type RBCs shows the same result, varifying the reliability of the method. The binding of B-type RBCs can be validated until the fold of antibody dilution is 4608 while the highest dilution for B3-type is 1024, showing an apparent distinction that is consistent with the previous illustration. The difference in antibody dilution folds implies the variation of the surface antigen expression.

Table 2. Serial antibody dilution for optical detachment tests using maximum laser power, $250 \mathrm{~mW}$ 


\begin{tabular}{c|ccc} 
Fold of antibody dilution & A-type RBCs & B-type RBCs & B3-type RBCs \\
\hline 1 & $\square$ & $\square$ & $\square$ \\
2 & $\square$ & $\square$ & $\square$ \\
4 & $\square$ & $\square$ & $\square$ \\
8 & $\square$ & $\square$ & $\square$ \\
16 & $\square$ & $\square$ & $\square$ \\
32 & $\square$ & $\square$ & $\square$ \\
64 & $\square$ & $\square$ & $\square$ \\
128 & $\square$ & $\square$ & $\square$ \\
256 & $\square$ & $\square$ & $\square$ \\
512 & $\square$ & $\square$ & $\square$ \\
1024 & $\square$ & $\square$ & $\square$ \\
2048 & $\square$ & $\square$ & $\square$ \\
2560 & $\square$ & $\square$ & $\square$ \\
3072 & $\square$ & $\square$ & $\square$ \\
3584 & $\square$ & $\square$ & $\square$ \\
4096 & $\square$ & $\square$ & $\square$ \\
4608 & $\square$ & $\square$ & $\square$ \\
5120 & $\square$ & $\square$ & $\square$
\end{tabular}

๑: RBC binding validated; $\square$ : RBC detached

In the second step, the antibody concentration continually decreases, and the optical power for detaching an RBC becomes lower than $250 \mathrm{~mW}$. The laser powers gradually decreased by $5 \mathrm{~mW}$ for further dilutions until $10 \mathrm{~mW}$, and then gradually decreased by $1 \mathrm{~mW}$. For instance, the B-type RBCs were detached when the dilution fold is 5120 at $250 \mathrm{mw}$ power in the first step tests. Subsequently, the applied powers were gradually decreased until the binding could be validated, i.e. the RBCs could not be detached. Finally, the binding strength was too small to oppose the optically detaching pull even using the lowest available power $(4 \mathrm{~mW})$. At this time, the antibody dilution fold reaches the maximum value. The results listed in Table 3. indicate that the binding of B-type RBCs can be validated until 7168-fold dilution while the highest dilution for B3-type RBCs is 2560. As a result, the more precise detection can be concluded.

Table 3. Serial antibody dilution for optical detachment tests using maximum laser power, $250 \mathrm{~mW}$ 


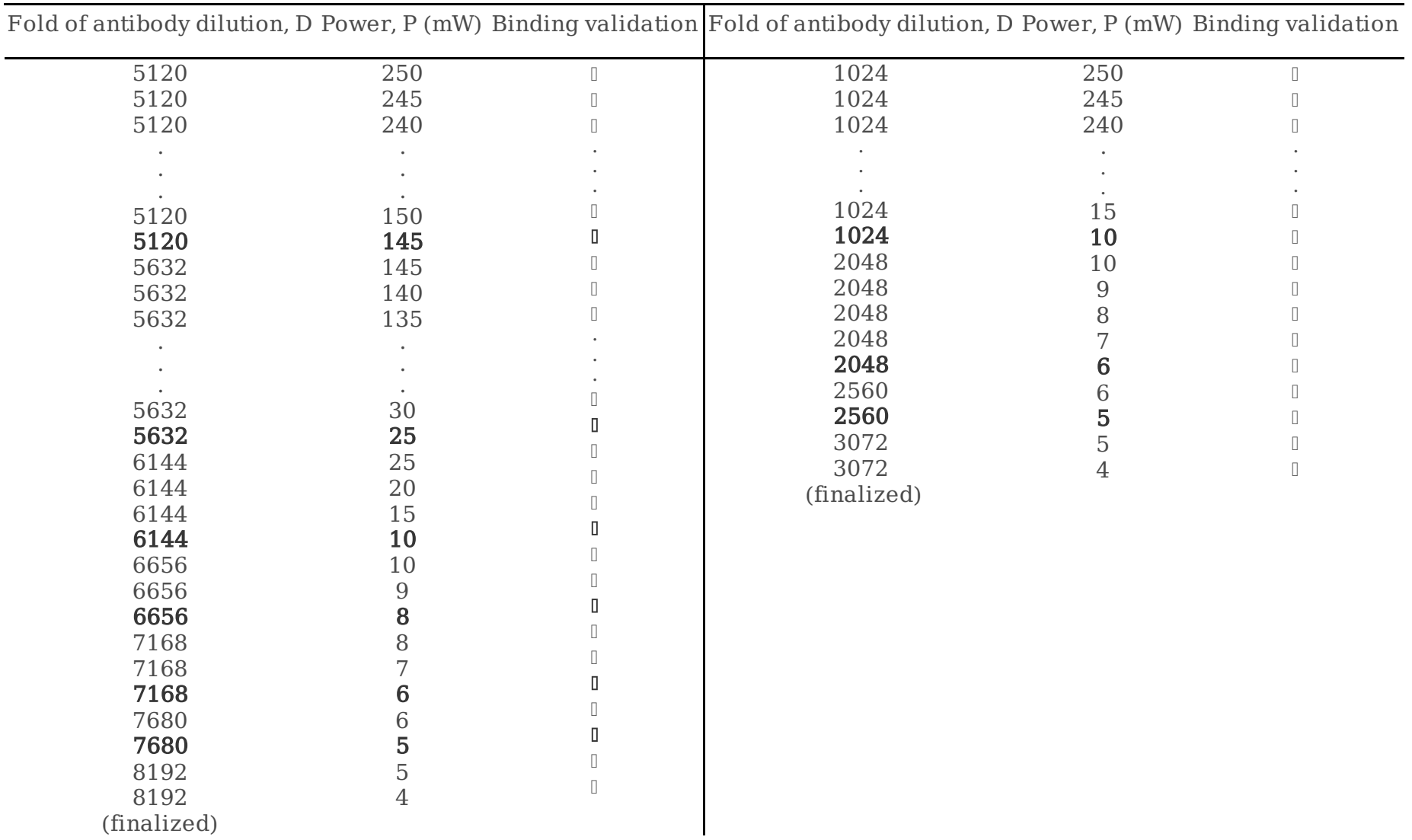

$\square:$ RBC binding validated; $\square$ : RBC detached

\subsection{Estimation of surface antigens expression variation}

Figure 4. plotted from the data in Table 3 shows that the antibody dilution fold $(D)$ is inversely proportional to the laser power $(P)$. The R-squares of B-type and B3-type are 0.99 and 0.98 , respectively, validating the method. The phenomenon implies the higher dilution (lower antibody concentration), the lower power (lower optical force) needed to detach the RBC binding. With this relationship, the RBC surface antigen expression variation can be semi-quantitatively analyzed. The maximum antibody dilution in the B-type test is 2.7 times (7168/2560) of the B3-type, meaning that the antigen expression on the B3-type RBC is $37.5 \%$ of which on the B-type RBC. The result is consistent with the previously mentioned literature $[11,12]$ using similar types of RBCs. Thus, the proposed approach was verified. After decades of development, convenient commercial optical tweezers machines and automatic manipulation systems with microfluidic chips [43-46] are becoming available and popular. The automatic operation would promise more optical detachment trials for more detailed dilution folds to obtain a higher resolution. Therefore, a more precise quantitative estimation could be obtained.

\section{Conclusion}

A novel methodology using the optical cell-detachment technique has been developed to estimate the variation of RBC surface antigen expression in this study. It suggests an alternative approach for the 
whole-cell-based antibody-antigen interaction analysis. The experiment results are consistent with literature that used conventional methods. One drop of blood from the fingertip was more than enough to achieve a sensitive detection. If necessary, a higher resolution of estimation could be obtained by more detailed dilution folds. The proposed concept is easy-to-use and intuitive without complicated biological treatment processes and optical force calculations. With the development of automatic routine procedures, we believe this approach could be widely capable with potential applications in the future, such as molecular biology, biophysics, and micro-/nano-technology engineering.

\section{Declarations}

Acknowledgements

The study was funded by the Ministry of Science and Technology (MOST 109-2637-E-166 -001 and NSC 102-2221-E-166-006). We thank Dr. HC Wang from the Dr. Lee Woman Clinic (Taipei, Taiwan) for providing professional opinions to help us refine this manuscript.

\section{References}

[1] G. Varady, J. Cserepes, A. Németh, E. Szabó, B.Sarkadi, "Cell surface membrane proteins as personalized biomarkers: Where we stand and where we are headed," Biomark Med. 2013, 7, 803-19.

[2] M. Fukuda, "Cell surface glycoconjugates as onco-differentiation markers in hematopoietic cells," Biochim. Biophys. Acta 1985, 780, 119-150.

[3] M.P. Banuls, A. Alvarez, I. Ferrero, A. Zapata, C. Ardavin, "Cell-surface marker analysis of rat thymic dendritic cells,"Immunology 1993, 79, 298-304.

[4] S. Takaishi, T. Okumura, S. Tu, S.S.W. Wang, W. Shibata, R. Vigneshwaran, S.A. K. Gordon, Y. Shimada, T.C. Wang, "Identification of gastric cancer stem cells using the cell surface marker CD44," Stem Cells 2009, 27, 1006-20.

[5] T.A. Springer, "Adhesion receptors of the immune system," Nature 1990, 346, 425-434.

[6] M.L. Olsson, H. Clausen, "Modifying the red cell surface: towards an ABO-universal blood supply," Br. J. Haemato/ 2008,140, 3-12.

[7] J.P. Sleeman, U. Kim, J. LePendu, N. Howells, T. Coquerelle, H. Ponta, P. Herrlich, “Inhibition of MT450 rat mammary tumour growth by antibodies recognising subtypes of blood group antigen B," Oncogene 1999, 18, 4485-4494.

[8] T. Nakagoe, A. Nanashima, T. Sawai, T. Tuji, M. Ohbatake, M. Jibiki, H. Yamaguchi, T. Yasutake, H. Ayabe, T. Matuo, "Expression of blood group antigens A; B and $\mathrm{H}$ in carcinoma tissue correlates with a poor prognosis for colorectal cancer patients," J. Cancer Res. Clin. Oncol. 2000, 126, 375-382. 
[9] J. Moldvay, P. Scheid, P. Wild, K. Nabil, J. Siat, J. Borrelly, B. Marie, G. Farré, T. Labib, G. Pottier, "Predictive survival markers in patients with surgically resected non-small cell lung carcinoma," Clin Cancer Res. 2000, 6, 1125-1134.

[10] D. Cho, D.J. Shin, M.H. Yazer, C.H. Ihm, Y.M. Hur, S.J. Kee, S.H. Kim, M.G. Shin, J.H. Shin, S.P. Suh, D.W. Ryang, "The M142T mutation causes B3 phenotype: three cases and an in vitro expression study," Korean J. Lab. Med. 2010, 30, 65-9.

[11] D.P. Chen, C.P. Tseng, W.T. Wang, C.F. Sun, "Genetic and mechanistic evaluation for the mixed-field agglutination in B3 blood type with IVS3+5G. A ABO gene mutation," PLoS One 2012, 7, e37272.

[12] T. Mori, Y. Katayama, "Signal amplification in flow cytometry for cell surface antigen analysis," J. Biochem. 2019, 166, 205-212.

[13] B. Arunachalam, G.P. Talwar, R. Raghupathy, "A simplified cellular ELISA (CELISA) for the detection of antibodies reacting with cell-surface antigens," J. Immunol. Methods. 1990, 135, 181-189.

[14] R.B. Efros, E. Zeller, L. Dillard, R.L. Walford, "Detection of antibodies to cell surface antigens by a simplified cellular ELISA (CELISA)," Tissue Antigens 1985, 25, 204-211.

[15] K. Svoboda, S.M. Block, "Force and velocity measured for single kinesin molecules," Cell 1994, 77, 773-784.

[16] K.C Neuman, A. Nagy, "Single-molecule force spectroscopy: optical tweezers, magnetic tweezers and atomic force microscopy ," Nat Methods 2008, 5, 491-505.

[17] R. Ros, F. Schwesinger, D. Anselmetti, M. Kubon, R. Schäfer, "Antigen binding forces of individually addressed single-chain Fv antibody molecules," Proc. Natl. Acad. Sci. USA 1998, 95, 7402-7405.

[18] T. Uchihashi, H. Watanabe, S. Fukuda, M. Shibata, T. Ando, "Functional extension of high-speed AFM for wider biological applications," Ultramicroscopy 2016, 160, 182-196.

[19] A. Ashkin, J.M. Dziedzic, T. Yamane, "Optical trapping and manipulation of single cells using infrared laser beams," Nature 1987, 330, 769-771.

[20] B.W. Yang, Y.H. Mu, K.T. Huang, Z. Li, J.L. Wu, Y.A. Lin, "The evaluation of interaction between red blood cells in blood coagulation by optical tweezers," Blood Coagul. Fibrinolysis 2010, 21, 505-510.

[21] A.J. Crick, M. Theron, T. Tiffert, V.L. Lew, P. Cicuta, J.C. Rayner, "Quantitation of malaria parasiteerythrocyte cell-cell interactions using optical tweezers," Biophys. J. 2014, 107, 846-853.

[22] K. Lee, M. Kinnunen, M.D. Khokhlova, E.V. Lyubin, A.V. Priezzhev, I. Meglinski, A.A. Fedyanin, "Optical tweezers study of red blood cell aggregation and disaggregation in plasma and protein solutions," J. Biomed. Opt. 2016, 21, 035001. 
[23] K.Y. Chen, T.H. Lin, C.Y. Yang, Y.W. Kuo, U. Lei, "Mechanics for the adhesion and aggregation of red blood cells on chitosan," J. Mech. 2018, 34, 725-732.

[24] R. Agrawal, T. Smart, J. Nobre-Cardoso, C. Richards, R. Bhatnagar, A.Tufail, D. Shima, P.H. Jones, C. Pavesio, "Assessment of red blood cell deformability in type 2 diabetes mellitus and diabetic retinopathy by dual optical tweezers stretching technique," Sci. Rep. 2016, 6, 15873.

[25] E. Ortiz-Rivero, K. Prorok, M. Skowicki, D. Lu, A. Bednarkiewicz, D. Jaque, P. Haro-González, "SingleCell Biodetection by Upconverting Microspinners," Small 2019, 1904154, 1-9.

[26] R. Zhu, T. Avsievich, A. Popov, I. Meglinski, "Optical Tweezers in Studies of Red Blood Cells," Cells 2020, 9, 545 .

[27] T. Fekete, M. Mészáros, Z. Szeglets, G. Vizsnyiczai, L. Zimányi, M.A. Deli, S. Veszelka, L. Kelemen, "Optically manipulated microtools to measure adhesion of the nanoparticle-targeting Ligand Glutathione to Brain Endothelial cells," ACS Appl. Mater. Interfaces 2021, 13, 39018-39029.

[28] I. Grexa, T. Fekete, J. Molnár, K. Molnár, G. Vizsnyiczai, P. Ormos, L. Kelemen, "Single-cell elasticity measurement with an optically actuated microrobot," Micromachines 2020, 11, 882, 1-13.

[29] S. Corsettia, K. Dholakia, "Optical manipulation advances for biophotonics in the 21 st century," J. Biomed. Opt. 2021, 26, 070602-1 23.

[30] P. Ermolinskiy, A. Lugovtsov, F. Yaya, K. Lee, L. Kaestner, C. Wagner, A. Priezzhev, “Effect of red blood cell aging in vivo on their aggregation properties in vitro: measurements with laser tweezers," Appl. Sci. 2020, 10, 7581, 1-10.

[31] C.L. Lin;; M.J. Pan, H.W. Chen, C.K. Lin, C.F. L, P. L. Baldeck, "Laser cross-linking protein captures for living cells on a biochip," In Frontiers in Biological Detection: From Nanosensors to Systems VII 2015 March, International Society for Optics and Photonics, 9310, 93100D.

[32] C.F. Lin, C.K. Lin, Y.J. Liu, C.H. Chiang, M.J. Pan, L.P. Baldeck, C.L. Lin, “Laser-induced cross-linking GFP-AcmA' bioprobe for screening Gram-positive bacteria on a biochip," RCS Adv. 2014, 4, 62882-62887.

[33] J.W. Chen, C.F. Lin, S.G. Wang, Y.C. Lee, C.H. Chiang, M.H. Huang, Y.H. Lee, G. Vitrant, M.J. Pan, H.M. Lee, Y.J. Liu, P.L. Baldeck, C.L. Lin, “New biodiagnostics based on optical tweezers typing red blood cells; and identification of drug resistant bacteria," In Optical Trapping and Optical Micromanipulation X 2013 September, International Society for Optics and Photonics, 8810, 88101N.

[34] D. Mazia, G. Schatten, W. Sale, "Adhesion of cells to surfaces coated with polylysine. Applications to electron microscopy," J. Cell Biol. 1975, 66, 198-200.

[35] W.M. Huang, S.J. Gibson, P.G.U.J. Facer, J. Gu, J.M. Polak, "Improved section adhesion for immunocytochemistry using high molecular weight polymers of L-lysine as a slide coating," Histochem. 
$1983,77,275-279$.

[36] S.L. Seurynck-Servoss, A.M. White, C.L. Baird, K.D. Rodland, R.C. Zangar, "Evaluation of surface chemistries for antibody microarrays," Anal. Biochem. 2007, 371, 105-115.

[37] A. Ashkin, "Forces of a single-beam gradient laser trap on a dielectric sphere in the ray optics regime," Biophys. J. 1992, 61, 569-582.

[38] W.Singer, S. Bernet, N. Hecker, M. Ritsch-Marte, "Three-dimensional force calibration of optical tweezers," J. Mod. Opt. 2000, 47, 2921-2931.

[39] D.G. Grier, "A revolution in optical manipulation," Nature 2003, 424, 810-816.

[40] W.H. Wright, G. J. Sonek, M. W. Berns, "Parametric study of the forces on microspheres held by optical tweezers," Appl. Opt. 1994, 33, 1735-1748.

[41] É. Sautner, K. Papp, E. Holczer, E. L. Tóth, R.Ungai-Salánki, B. Szabó, P. Fürjes, J. Prechl, “Detection of red blood cell surface antigens by probe-triggered cell collision and flow retardation in an autonomous microfluidic system," Sci. Rep. 2017, 7, 1008.

[42] J.P. Cartron, A. Gerbal, N.C. Hughes-Jones, C. Salmon, " 'Weak A' phenotypes: relationship between red cell agglutinability and antigen site density," Immunology 1974, 27, 723-727.

[43] P. Jing, Y. Liu, E.G. Keeler, N.M. Cruz, B.S. Freedman, L.Y. Lin, “Optical tweezers system for live stem cell organization at the single-cell level," Biomed. Opt. Express 2018, 9, 771-779.

[44] K. Lee, E. Shirshin, N. Rovnyagina, F. Yaya, Z. Boujja, A. Priezzhev, C. Wagner, "Dextran adsorption onto red blood cells revisited: single cell quantification by laser tweezers combined with microfluidics," Biomed. Opt. Express 2018, 9, 2755-2764.

[45] A. Shakoor, B. Wang, L. Fan, L. Kong, W. Gao, J. Sun, K. Man, G. Li, D. Sun, "Automated optical tweezers manipulation to transfer mitochondria from fetal to adult MSCs to improve antiaging gene expressions," Smal/ 2021, 2103086: 1-17

[46] H. Wang, A. Enders, J.-A. Preuss, J. Bahnemann, A. Heisterkamp, M. L. Torres-Mapa, "3D printed microfluidic lab-on-a-chip device for fiber-based dual beam optical manipulation," Sci. Rep. 2021, 11, 14584.

\section{Figures}




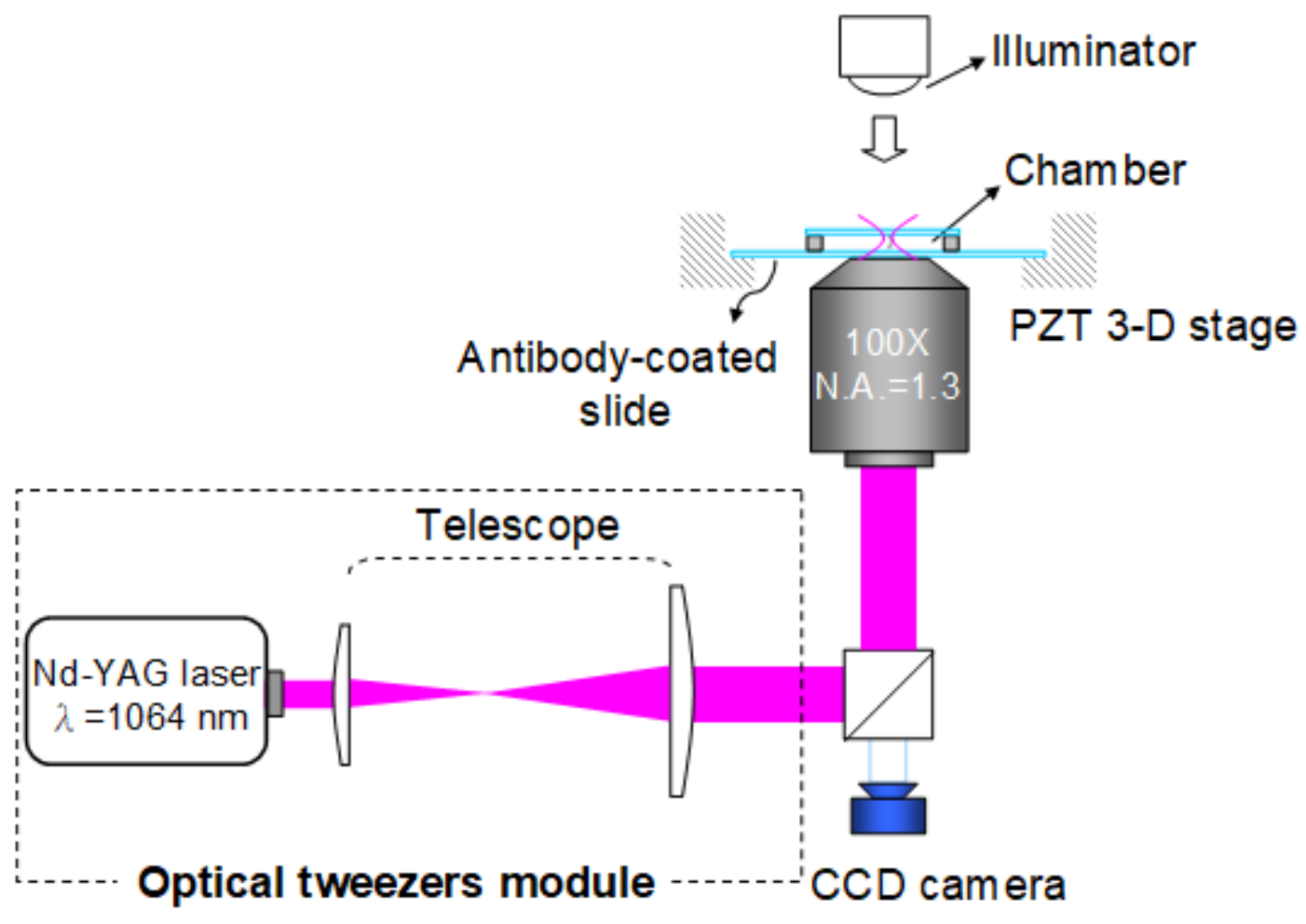

Figure 1

Optical tweezers setup: a schematic figure of optical tweezers and the detail (not in scale) of the sample chamber 


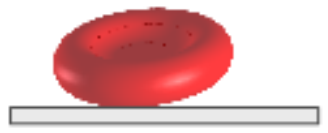

(a) Optical tweezers turns off

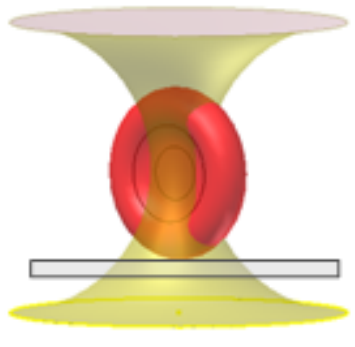

(b) Optical tw eezers tum on

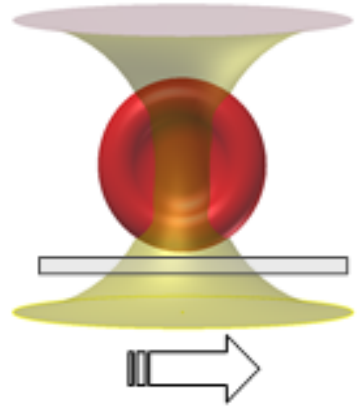

(c) Dragging speed $=5 \mu \mathrm{m} / \mathrm{sec}$; power $\geqq$ threshold

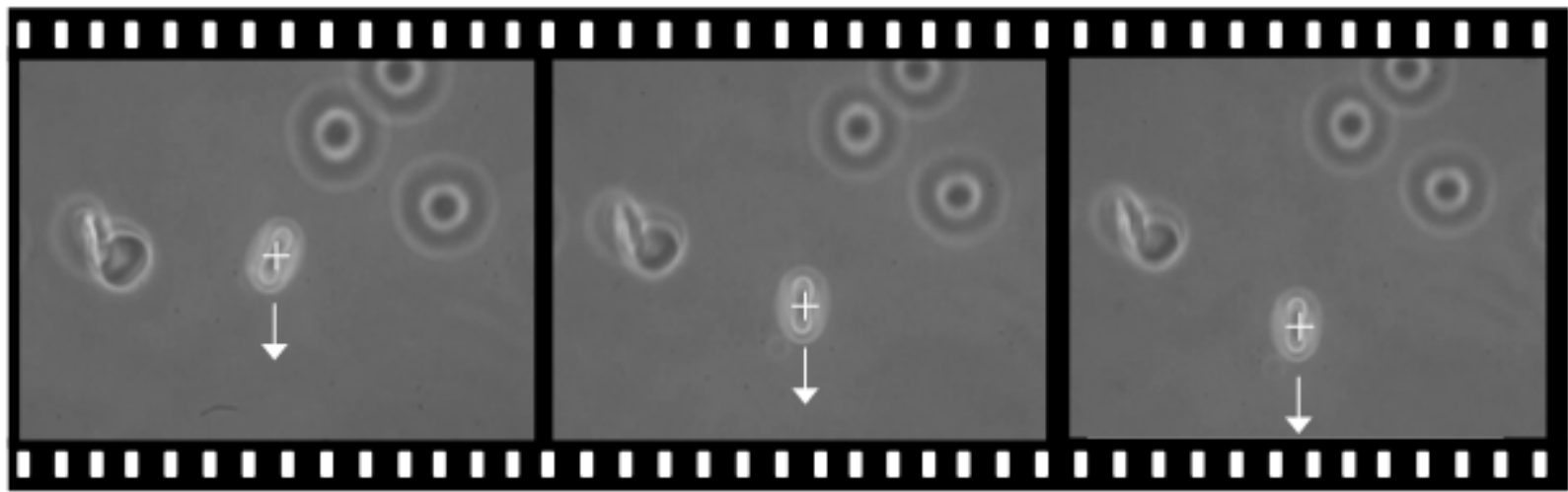

0 second

1 second

1.5 second

(d) $\mathrm{RBC}$ is dragged using optical tw eezers.

\section{Figure 2}

Schematic illustration (not in scale) of an RBC trapped by optical tweezers on a non-specific antibodyantigen interaction surface: (a) RBC lies on the surface when the optical tweezers turns off; (b) RBC stands up after the optical tweezers turns on; (c) the suspended RBC is freely dragged by the optical tweezers; (d) the manipulation films (Visualization 1): the cross is the position of the optical tweezers trapping spot; the arrow presents the dragging direction. 
(a) Detail of the RBC stuck on the antibody-coated surface
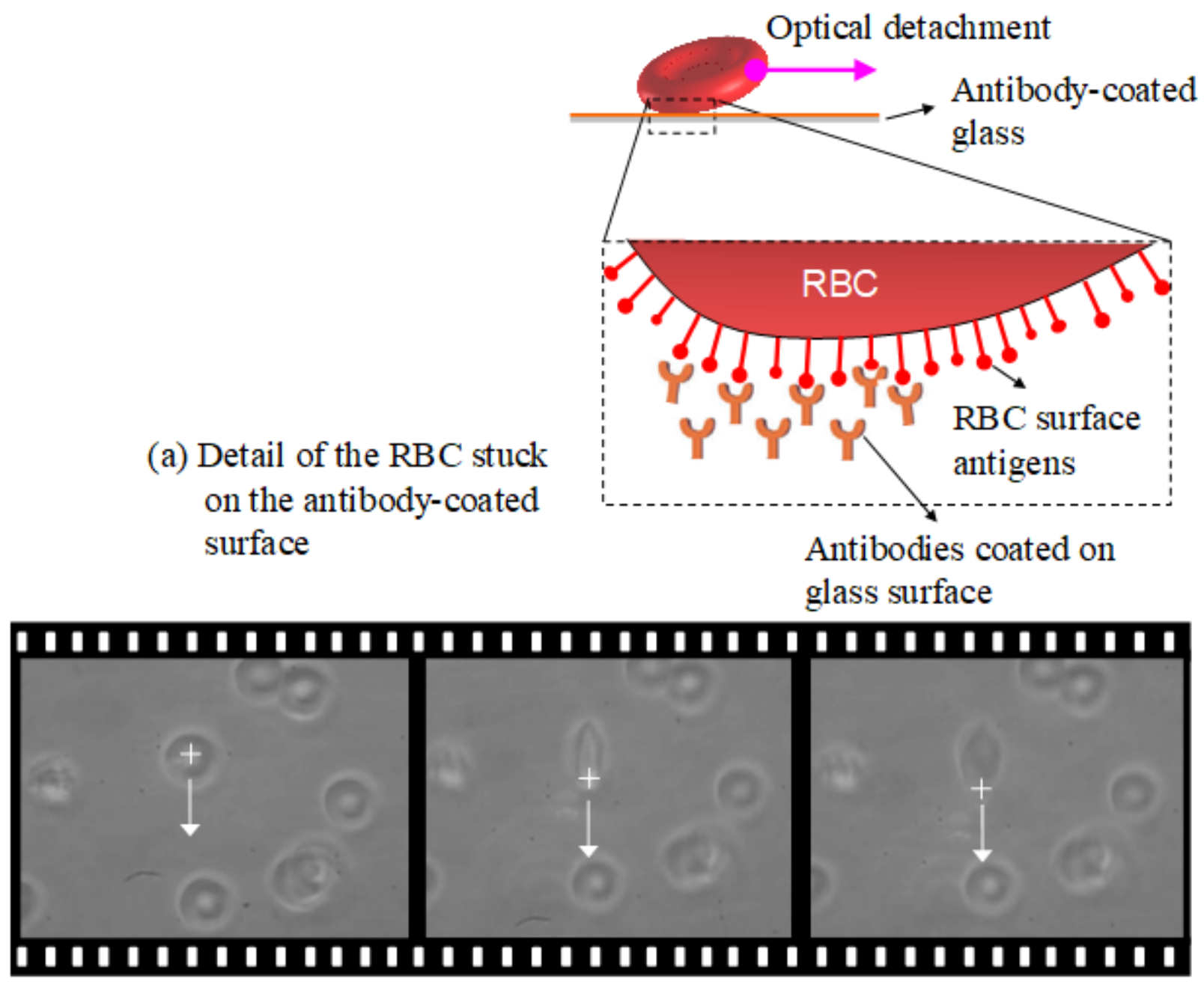

0 second

1 second

1.5 second

(b) $\mathrm{RBC}$ is stretched by optical tweezers

Figure 3

Schematic illustration (not in scale) detailing RBC attachment to the antibody-coated surface. (b) RBC is detached by optical tweezers but still stuck on the antibody-coated surface (Visualization 2). 


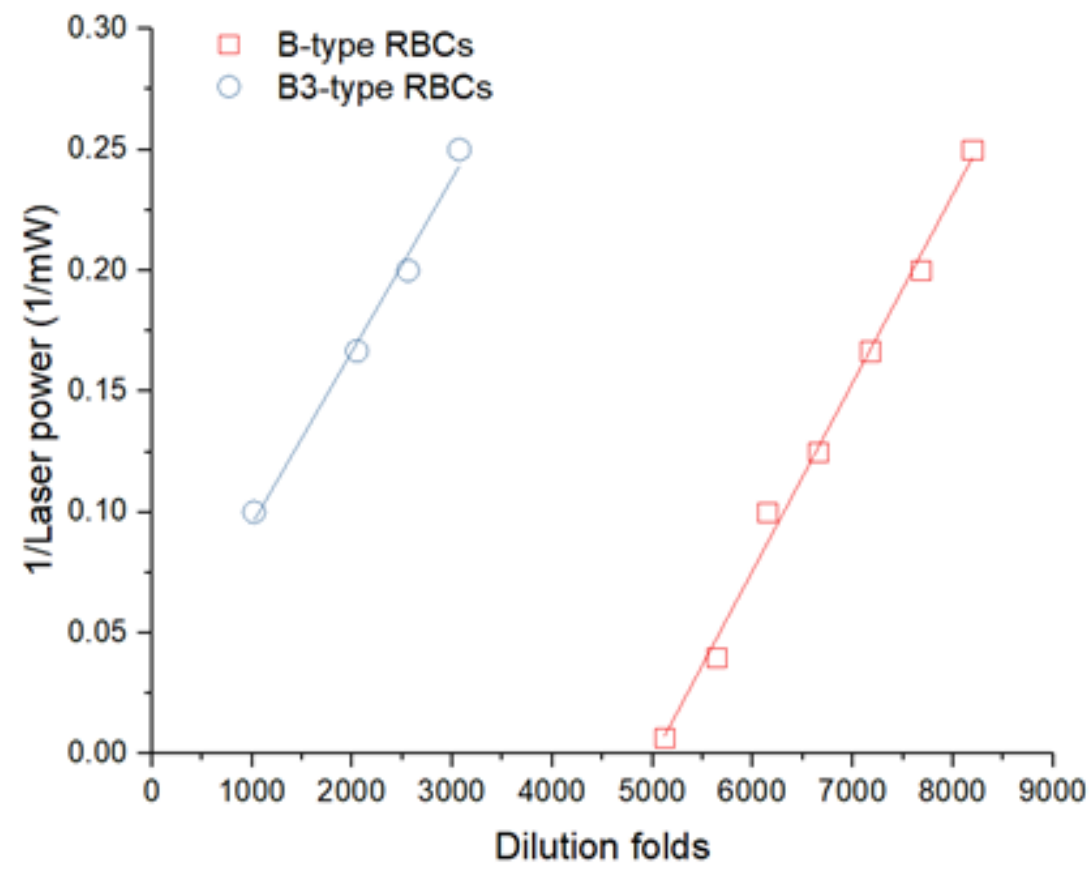

Figure 4

The relationship between fold dilution and 1 /laser power. 